\title{
Islamic Affinities with New Sciences and Technologies
}

\author{
Eric Winkel*
}

Science and Technology (ST) understood as mechanical Newtonian physics and industry has indeed bypassed Muslim societies - and that's a good thing. Because with the new ST Muslims can become full participants rather than passive recipients.

From the 1960s and 1970s, a few Muslim thinkers sounded the alarm about ST (e.g., Seyyed Hossein Nasr, Ismail Faruqi, and Syed Muhammad Naquib al-Attas). They were aware that Muslim societies were trying to catch up and join a system of knowledge and technological tools that were both ontologically opposed to Islam and harmful to Muslim cultures. At the same time, thinkers in the West were horrified at the implications of ST for the natural world and for human freedom (e.g., Theodore Roszak, Jerry Mander, Lewis Mumford, Jacques Ellul). Today, from intellectual discourse to popular culture and movies, the idea that the old science and technology has gone wrong is easy to find and accept.

What is the 'New Science and Technology'? First, it is something that sees itself as a critique, rejection, or improvement on what came before. Industry is dehumanising, petroleum-intensive, toxic, and consumerist. The old science assumes a mechanical world where we can predict, and control, nature. In contrast, the New ST gives preference to the small, human scale; to the local; to sustainability; to organic and healthy; to taste, not blind consumption. The science is of systems that are complex and nonlinear; huge traffic jams may result from only one car braking for one second; patterns emerge from what looks like chaos. These 'emergent' patterns show robustness and demonstrate new and desirable qualities only after they spin out of our control. The New ST is interested in networks and how tiny, even individual, inputs have profound consequences down the road. The New ST is interested in democracy, in systems that function without control from above, and in ways that are user-friendly and initiated and supported by users.

E.W. Lawrimore, writing in 2004, speaks of "a profound truth so important for 21 st Century leaders and organizations: Most organizations today were established on linear, mechanical principles, the organization as a machine, producing goods and services. Science abandoned the mechanical view of the universe almost 100 years ago. Most of us are still operating on a worldview that is left over from the machine age and is 100 years out of date! This is the Information Age, and nonlinear, complex adaptive systems are the best way to understand systems involving people."

Contemporary science still has its old ways, and contemporary technologies are often as destructive and harmful as they were before, even if a 'green' face has

* Dr Eric Winkel is Principal Research Fellow at IAIS Malaysia. 
been painted on. The 'net generation' has very intriguing possibilities, but there are negatives as well - is all that activity merely distraction? Aldous Huxley was worried about "the development of a vast mass communications industry, concerned in the main neither with the true nor the false, but with the unreal, the more or less totally irrelevant. In a word, they failed to take into account man's almost infinite appetite for distractions."

Fully aware of these criticisms, we can still make a distinction between two different styles of ST, one largely industrial and the other given names like 'knowledge-intensive' or 'green' or 'sustainable' or 'humanscale'. In the area of science, names that signal this other intent include 'complexity', 'chaos', 'emergent', and 'quantum'.

Many pieces and aspects of the New ST show a surprising affinity with Islamic civilisation. The spread of knowledge with the internet has remarkable similarities with paper and printing in the historical Arab-Islamic world, where knowledge was disseminated over long distances and among a fairly widely diverse, public audience. As Muslim societies seek to participate in this new realm, where they were previously passive recipients, resonances with the Islamic heritage could mean that this participation will become authentic, integral, and full. The first effort, then, is to engage the fullness of this heritage with the 'now'. Democratic use of technologies, networks, patterns in the natural world, and the criterion of 'beneficial' (read 'green') applied to knowledge and 'not harmful' applied to technology are all examples desired by New ST and enjoined by Islamic civilisation. This effort is one of language, speaking a language that is inspired by Islam and familiar to the global 'now'. Going back to the 'family' metaphor of 'familiar', in a sense this is introducing long-lost brothers to each other: they have had very different experiences, but they also recognise kinship.

When ST was engrossed by the Doctrine of Self-Interest, there was not much interest in hearing voices from Islamic and other civilisations that said cooperation is fundamental to human nature. Scientists with the Santa Fe Institute have documented the failure of the 'canonical selfishness based model', and the field is open to Muslim contribution on cooperation. When nature and resources are seen as utterly exploitable and consumable, there was not much room for people who speak of the earth as our mother (as in the statement by Prophet Muhammad, "And be mindful of the earth, because she is your mother"). With a growing sense of dystopia, the field is open for Muslims and others to speak of our connections to the earth; and to reject the arrogance that we must 'save the planet', because it is we who are the weak party, and we who need to be saved. This might be the time to leave the margins of science, technology, and history that Muslims were written into by a dominant culture and to enter fully into the new field of ST that is under no one's control. 